\title{
Variation in Deformation Behaviors Along the Transverse Direction During the Warm Rolling of a 1480-mm-Wide AZ31B Plate
}

\author{
Chenchen Zhi', Lifeng Ma ${ }^{1,2^{*}}$ (D), Weitao Jia², Pengtao Liu², Qichi Le ${ }^{3}$, Zhiquan Huang ${ }^{2}$ and Tingzhuang Han²
}

\begin{abstract}
A decrease in the weight of aerospace vehicles, large ships, weapons, and high-speed trains will increase the demand for wide-width magnesium alloy plates and their composite parts to replace steel and plastic. An investigation was conducted to study the variation in deformation behaviors along the transverse direction during the warm rolling of a 1480-mm-wide AZ31B plate. A uniaxial thermal compression test with a $59 \%$ reduction was performed at different positions on a $13.7-\mathrm{mm}$-thick rolled plate along the width direction at a temperature of $220^{\circ} \mathrm{C}$ and $270{ }^{\circ} \mathrm{C}$ and strain rate of $15 \mathrm{~s}^{-1}$. At the same time, the 13.7- $\mathrm{mm}$-thick plate was rolled in a single pass to $5.6 \mathrm{~mm}$ on a mill with a 1725-mm-wide roll to confirm the thermal deformation behavior and the dynamic recrystallization (DRX). The results show that the main texture type does not change and the grain size does not have a clear deflection when the magnesium alloy plate reaches a certain value under rolling accumulative reduction. The grain size of a 13.7-mm-thick plate increases with a decrease in the distance to the center layer in the thickness direction. In the width direction, the edge (R6) first decreases and then increases toward the symmetric plane (R1). The critical stress required for dynamic recrystallization in the transition zone $\mathrm{R} 3$ of the rolled plate width is minimum, and the average grain size is minimum owing to the relatively complete recrystallization.
\end{abstract}

Keywords: Warm rolling, Deformation behavior, 1480-mm in width, AZ31B plate, Dynamic recrystallization

\section{Introduction}

Magnesium alloys have been widely used as structural materials for advanced applications owing to their excellent properties such as low density $\left(1.738 \mathrm{~g} / \mathrm{cm}^{3}\right)$ and high specific strength [1]. However, Mg has limited slip systems owing to the hexagonal close-packed structure, which results in $\mathrm{Mg}$ and its alloys having lower strength and poor formability during plastic deformation. The abovementioned characteristics of magnesium alloys lead to defects, such as cracks, after deformation [2,3]. Therefore, in recent years, studies on magnesium alloys have received increasing attention, especially in terms

\footnotetext{
*Correspondence: mlf_zgtyust@163.com

${ }^{1}$ School of Mechanical Engineering, Taiyuan University of Science and Technology, Taiyuan 030024, China

Full list of author information is available at the end of the article
}

of the optimization of structural properties and performance improvement [4]. In addition, the thermal deformation process is dominated by DRX due to the low stacking fault energy of magnesium alloys [5]. It is essential to study the DRX of magnesium alloy in the process of hot work owing to the considerable effect of DRX on grain refinement during deformation and on improving mechanical properties [6].

Because the thermal deformation behavior of magnesium alloys is typically analyzed at high temperatures to improve their processing performance, DRX is essential in the evolution of microstructures [7]. More importantly, DRX is an important factor for improving plasticity and refining the grain size of magnesium alloys [8]. The DRX kinetic model of magnesium alloy can provide DRX fraction and DRX grain size information [9]. Many studies have confirmed that 
the microstructure and deformation characteristics of magnesium alloys can be predicted well by calculating the dynamic model of DRX [10-12]. Surveys conducted by Jian [13] have shown that the improvement in the DRX behavior of magnesium alloys (by adding alloy elements) and the heat treatment performance can be improved to reach the energy standard of industrial production. Some scholars have studied the effect of temperature [14], initial texture [15], and other deformation conditions on the microstructure and mechanical properties of magnesium alloys. Other studies have focused on the thermal deformation behavior of the alloy with the initial as-cast state under different conditions [16]. However, under the same deformation conditions, the deformation behaviors in different regions of the same original material have been rarely studied, especially for plates with large-width. Owing to the potential of energy conservation and emission reduction in the machinery and equipment industry, magnesium alloy products have great application value in engineering applications, and the demand for large-size plates is increasing [17]. Liao [18] analyzed the microstructure and mechanical properties of magnesium alloy plates with a width of $300 \mathrm{~m}$ in different extrusion regions. In particular, large-size plates are more likely to produce side cracks and other defects owing to their larger width, which reduces production efficiency [19].

In this study, rolled intermediate magnesium alloy plates with a width of $1480 \mathrm{~mm}$ were evaluated and differences in their thermal compression deformation behavior were analyzed by obtaining several patterns along the width direction. Then, the actual rolled plate microstructure with the same deformation reduction was tested and verified. The main purpose of this study is to evaluate the difference in deformation behaviors in different regions along the width direction during the rolling process of the wide-width magnesium alloy plate.

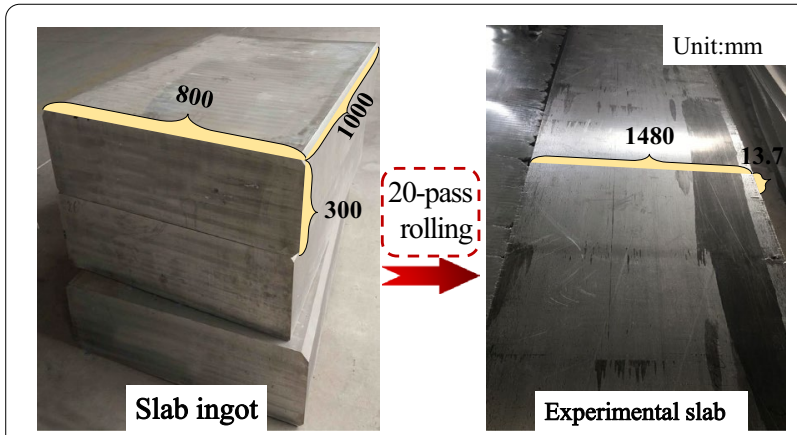

Figure 1 Parameters of the hot rolling mill and the source of the plates used in the experiment

\section{Materials and Methods}

\subsection{Experiment Materials}

The original material used in this study was an as-cast AZ31 slab ingot prepared by the low-frequency electromagnetic casting process, with a thickness of 300 $\mathrm{mm}$ and width of $800 \mathrm{~mm}$. The experimental plate was a 20-pass symmetrically rolled ingot with a thickness of $13.7 \pm 0.2 \mathrm{~mm}$ and a width of $1480 \mathrm{~mm}$ (excluding edge crack parts), which was fabricated by a single-stand fourhigh mill with $\Phi 810 \mathrm{~mm} \times 1725 \mathrm{~mm}$ work rolls (Figure 1).

During the preparation process, the intermediate annealing and heat compensation process was not used. As given in Table 1, the chemical composition of the material was obtained by inductively coupled plasma analysis. AZ31 was selected as the experimental material because its main phase is Al12Mg17 which was so few that its effect on the microstructure during deformation can be ignored.

Figure 2 shows the optical microscopy (OM) images acquired from the TD-ND cross-section at the center of the width of the rolled plate. The microstructure of the hot-rolled AZ31 Mg alloy has an equiaxially recrystallized structure with a highly scattered grain size distribution ranging from $8 \mu \mathrm{m}$ to $110 \mu \mathrm{m}$. It is determined that partial recrystallization occurs during hot rolling, which leads to inhomogeneous microstructures. In addition, new and fine recrystallized grains are characterized by a necklace in the vicinity of high-sized grains (labeled

Table 1 Chemical composition of the AZ31B alloy (wt\%)

\begin{tabular}{llll}
\hline Al & Zn & Mn & Mg \\
\hline 3.18 & 0.76 & 0.25 & Bal. \\
\hline
\end{tabular}

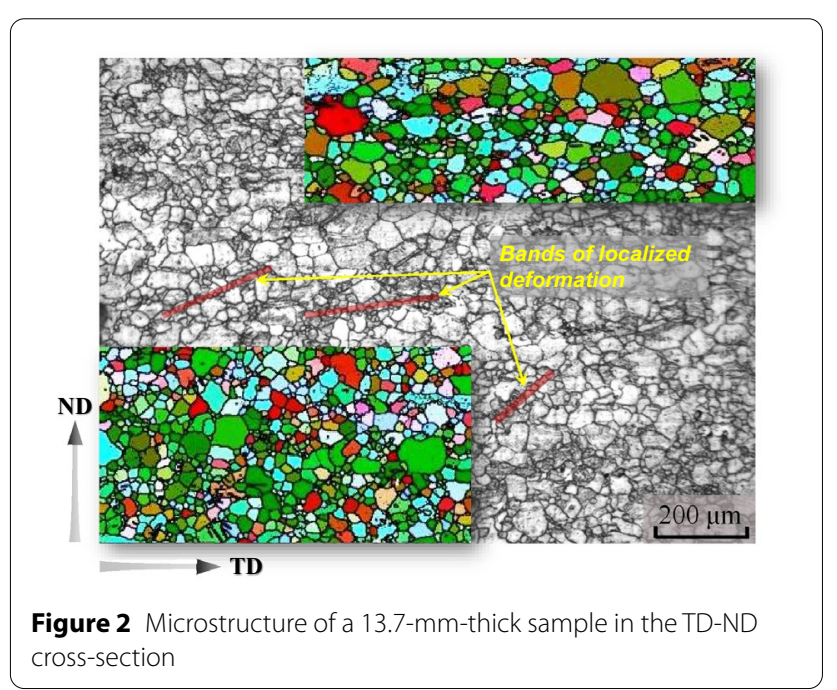


as a line in Figure 2), which confirms rotation recrystallization [20]. As proposed by Ion [6] and Valle [21], the appearance of ductile shear zones and bands of localized deformation (as marked in Figure 2) can be explained well by this recrystallization mechanism. Moreover, the origin of these ductile shear zones considerably differs from that of shear bands contributed by plastic instability.

\subsection{Experimental Procedure}

Although the AZ31 magnesium alloy can accommodate a very large size reduction at high temperatures in a single pass, the edge crack is serious during the $80 \%$ reduction rolling process [22]. Therefore, considering the energy saving, high efficiency, and high performance in industrial production, a $59 \%$ reduction was selected to produce a plate with a thickness of $5.6 \mathrm{~mm}$. The use of the same rolling mill further reduced the thickness of the as-rolled AZ31 plate from $13.7 \mathrm{~mm}$ to $5.6 \mathrm{~mm}$ in one pass. Prior to rolling, both the AZ31 plate and work rolls were not reheated owing to the presence of residual heat after the 20-pass rolling process; the temperature before rolling was $265{ }^{\circ} \mathrm{C}$ with a fluctuation range of $\pm 15{ }^{\circ} \mathrm{C}$ in the width direction, and the temperature after rolling was $105 \pm 20^{\circ} \mathrm{C}$. The rolling speed was set as $60 \mathrm{~m} / \mathrm{min}$, whereas rolling was performed under the non-lubricated condition.

What we desire is an arm exoskeleton which is capable of following motions of the human upper-limb accurately and supplying the human upper-limb with proper force feedback if needed. In order to achieve an ideal controlling performance, we have to examine the structure of the human upper-limb.

The Gleeble-simulated process, which involves uniaxial hot compression tests, was used to examine the warm deformation properties in the transverse direction of the AZ31 Mg alloy plate during the abovementioned experimental rolling process. For the compression tests, six cylindrical specimens $(\Phi 8 \mathrm{~mm} \times 12 \mathrm{~mm})$ were machined from the as-rolled AZ31 plate $(13.7 \mathrm{~mm})$ in the same direction as the compression axis aligned in the normal direction and named C1, C2, C3, C4, C5, and C6 (Figure $3 a$ ). Figure 3 a shows the schematic of the corresponding sampling sites between hot compression and rolling, where compression samples are acquired on a $13.7-\mathrm{mm}$ rolled sheet. Samples C1, C2, C3, C4, C5, and C6 were acquired as original samples for the thermal compression simulation test, through which the microstructure evolution and deformation features in the transverse direction can be characterized when the plate is compressed from $13.7 \mathrm{~mm}$ to $5.6 \mathrm{~mm}$ after $59 \%$ reduction. Owing to the small width spread of the magnesium plate during rolling from $13.7 \mathrm{~mm}$ to $5.6 \mathrm{~mm}$, the effect of the spread on the deformation behavior in the width direction is ignored. Figure $3 \mathrm{~b}$ shows the schematic of the actual rolling plate sample. It can be confirmed that after rolling the plate from $13.7 \mathrm{~mm}$ to $5.6 \mathrm{~mm}$, the width is very small and can be neglected in the study of the width difference.

According to Sims' equation, the true strain rate during experimental rolling can be calculated as Eq. (1) [23]:

$$
\dot{\varepsilon}=\frac{\pi}{30} N \sqrt{\frac{R}{H}}\left(\sqrt{\frac{1}{\xi}} \ln \frac{1}{(1-\xi)}\right) \approx 15,
$$

where $\xi$ is rolling reduction rate, $\xi=(H-h) / H, H(\mathrm{~m})$ is the entry thickness of strip and $h(\mathrm{~m})$ is the thickness of rolled strip, $R$ is roll radius and $N$ is Roll speed in revolutions per minute.

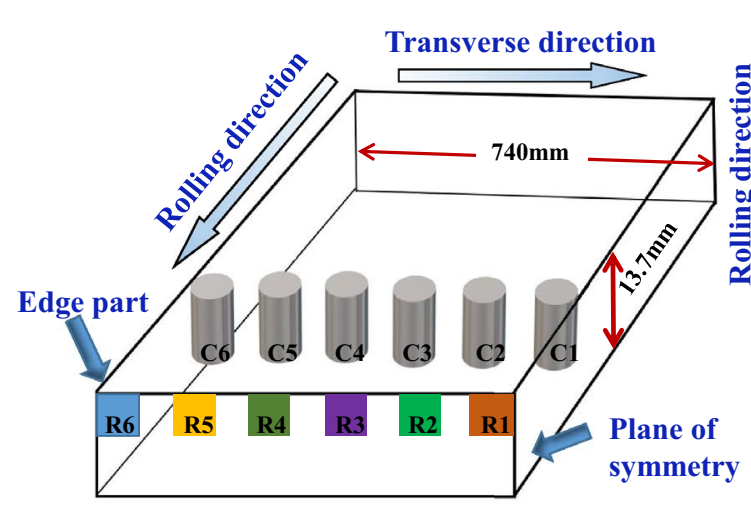

a

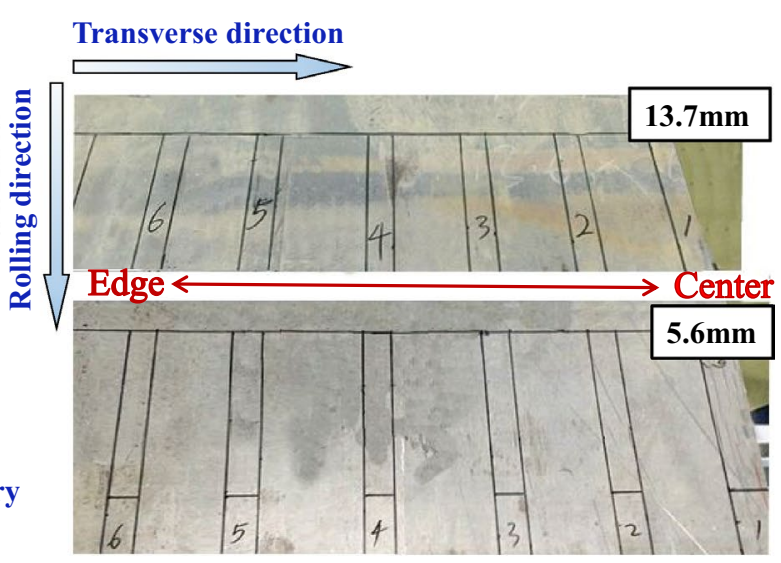

b

Figure 3 Schematic of the corresponding sampling sites between hot compression and rolling: (a) schematic of compression, (b) schematic of the actual rolling 
Therefore, uniaxial hot compression tests were conducted at $220{ }^{\circ} \mathrm{C}$ and $270{ }^{\circ} \mathrm{C}$ at a strain rate of $15 \mathrm{~s}^{-1}$ using the Gleeble-3800 system. Specimens were heated up to the target temperature at $5{ }^{\circ} \mathrm{C} / \mathrm{s}$ and held for $90 \mathrm{~s}$ to obtain a uniform temperature distribution. The XRD texture samples were selected from the center of the rolled plate along the width of the plate and labeled as R1, R2, R3, R4, R5, and R6, as shown in Figure 3b. After sandpaper polishing to 5000\#, the surface of the samples was polished by mechanical polishing and etched with $5 \%$ nitric acid alcohol to remove the surface stress layer. Then, the texture was determined by the Schulz backreflection method using an X'pert PRD w3040/60 diffractometer manufactured by the Philips Company at the testing center in Northeastern University in China. The EBSD samples were prepared by electrochemical polishing with a solution of ACII, at a voltage of $20 \mathrm{~V}$ and a temperature of $25^{\circ} \mathrm{C}$ below zero for $45-50 \mathrm{~s}$. Variations in the microstructure of the AZ31 plate (for thicknesses of $13.7 \mathrm{~mm}$ and $5.6 \mathrm{~mm}$, Figure $3 \mathrm{~b}$ ) along the transverse direction were investigated using OM. The grain size was measured by an optical microscope and the Heyn lineal intercept method, which was used to count equiaxed grains and microstructures that were clearly not equiaxed [24].

\section{Results and Discussion}

\subsection{Microstructures of the Sample Material}

Figure 4 shows the microstructure evolution of a 13.7-mm-thick rolled plate in different regions along the width and thickness directions, which are all displayed as equiaxed grains. From the surface layer to the center layer, it can be seen that the distribution of grain size is not consistent in the thickness direction. The average grain size increases from the surface layer to the center layer. There is a higher proportion of fine grains in the surface layer probably because of the original fine crystal structure formed by chilling during casting. Furthermore, fine grains are more likely to undergo DRX than large grains in the process of hot deformation; thus, surface grains retain a finer state. An alternative explanation is that the surface grain is subjected to a certain degree of shear force during rolling deformation.

The grain size distribution of different regions along the transverse and the thickness directions are shown in Figure 5. The microstructures in the three layers vary in a similar way. The average grain size first decreased and then increased from the edge (R6) to the symmetrical plane (R1) along the width direction. The statistics of grain size exhibited normal distribution, which indicated that the proportion of fine grains gradually increased. Owing to the difference in temperature and deformation stress, recrystallization occurred later in the edge

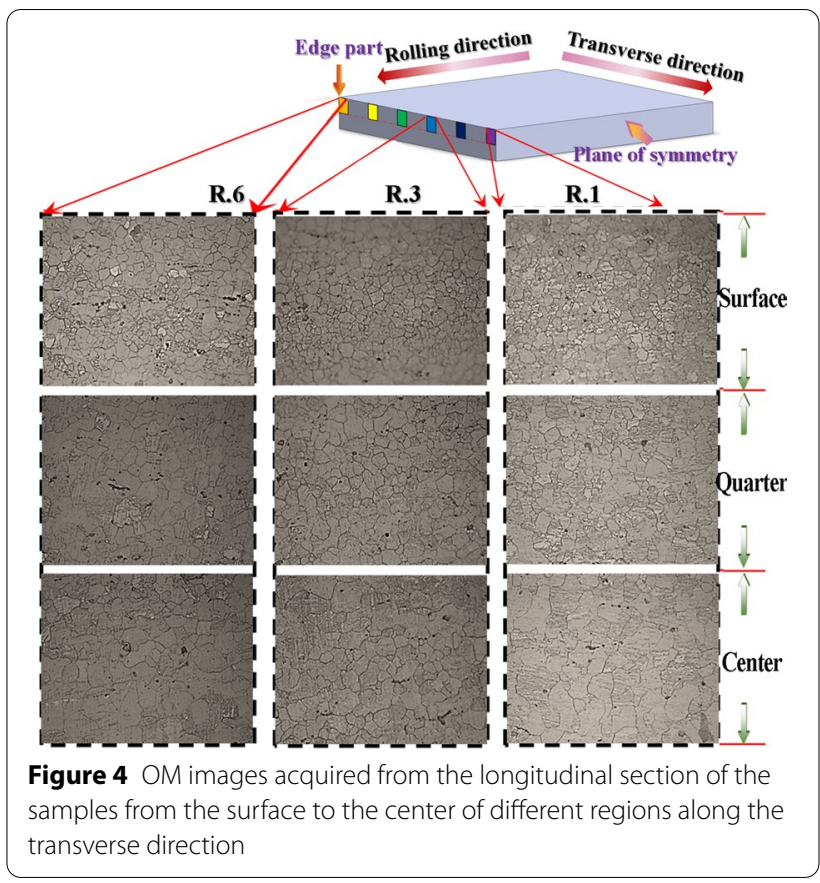

part than in the central part. Thus, the proportion of fine grains in R6 was approximately the same as that in R1; however, in R3, the proportion was much larger. There were more coarse grains with a grain size of approximately $18-32 \mu \mathrm{m}$ in the center layer, especially in regions $\mathrm{R} 1$ and R3, and the distribution of grains was relatively equal. DRX may occur more easily in the central layer of the rolled plate owing to the lower heat loss [25]. Therefore, the grain at R1 underwent complete DRX, and the grain started to grow while DRX began in other regions.

\subsection{Flow Stress Curves}

The true stress-true strain curves recorded on the specimens from different regions under isothermal compression at $220{ }^{\circ} \mathrm{C}$ and $270{ }^{\circ} \mathrm{C}$ and at a strain rate of $15 \mathrm{~s}^{-1}$ are shown in Figures $6 \mathrm{a}$ and $8 \mathrm{~b}$, respectively. It is evident that the flow stress is largely related to strain and deformation temperature. Therefore, the thermal deformation behavior of different regions in the transverse direction of the magnesium alloy plate can be studied by analyzing the compression stress-strain curves. The stressstrain curves of the AZ31 magnesium alloy were divided into three stages, as shown in Figure 6; the stress sharply increased with an increase in strain in the first stage, which was owing to the strong work hardening caused by an increase in the dislocation density. In the second stage, flow stress slowly increased with an increase in strain until it reached a peak. The combined action of dynamic recovery (DRV) and DRX became increasingly intense to offset part of the work hardening, and 

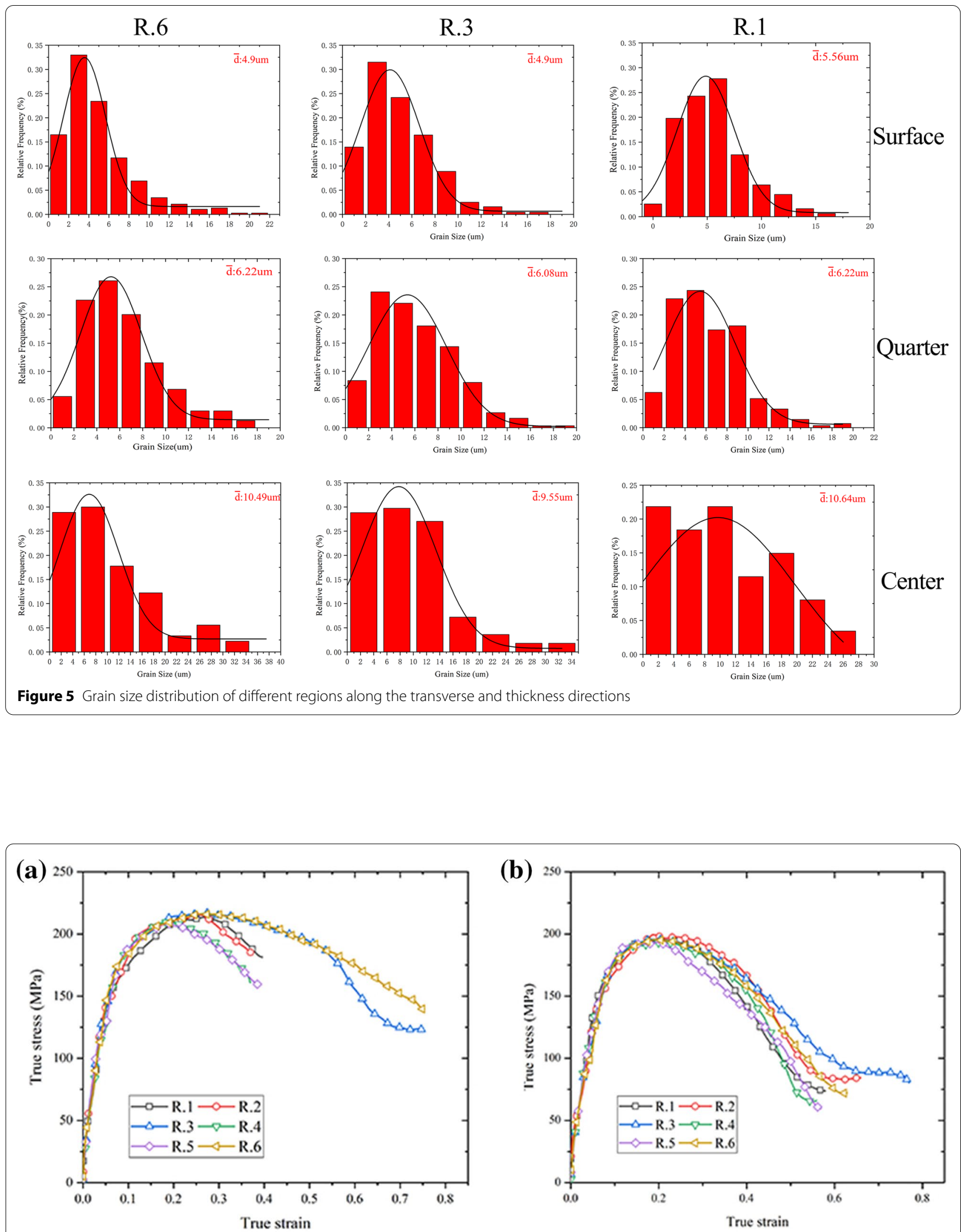

Figure 6 True stress-true strain curves of different regions at a strain rate of $15 \mathrm{~s}^{-1}$ and at (a) $220^{\circ} \mathrm{C}$ and (b) $270^{\circ} \mathrm{C}$ 
recrystallized grains began to nucleate at the original grain boundary during this stage. A variation in the last stage was the competition between work hardening and softening caused by DRX. Figure 6 shows that most areas of the AZ31 rolled plate are characterized by typical DRX softening at $220^{\circ} \mathrm{C}$ and $270{ }^{\circ} \mathrm{C}$.

At $220^{\circ} \mathrm{C}$, samples (except for R6 and R3 at the extreme edge) cannot achieve stable stress during deformation, which may be caused by incomplete DRX or flow instability [26], as shown in Figure 6a. The stress-strain curves of six different regions showed a clear softening behavior at $270{ }^{\circ} \mathrm{C}$. This phenomenon was primarily attributed to the acceleration of migration rate of grain boundaries with an increase in the temperature; thus, dislocation, which accumulated at the grain boundaries, moved or disappeared with the migration of grain boundaries, with decreased work hardening [27]. By comparing the stressstrain curves at $220{ }^{\circ} \mathrm{C}$ and $270{ }^{\circ} \mathrm{C}$, the peak stress of the true stress-true strain curve demonstrated a reduction tendency with an increase in the deformation temperature. The strain corresponding to the peak stress changed to 0.2 from the highest value of 0.28 , which indicated that DRX occurred at higher temperatures [28].

\subsection{Onset of DRX}

It can be seen from the stress-strain curve that temperature has a considerable effect on the steady-state rheological stress and peak stress, and it determines the deformation and recrystallization mechanisms [29]. An important index to measure the degree of DRX is the critical strain, which cannot be intuitively reflected by the flow stress curve. As shown in Figure 7, the $-(\partial \theta / \partial \sigma)-\sigma$ curves at different temperatures can be obtained by fitting the work hardening rate of the flow stress curve in different regions. The minimum values in the $-(\partial \theta / \partial \sigma)-\sigma$ curves corresponded to the critical strain of DRX occurrence [30].

When the thermal deformation temperature is $220^{\circ} \mathrm{C}$, the corresponding flow stress from R1 to R6 is 197.8, $201.4,167.3,202.8,201.7$, and $188.6 \mathrm{MPa}$, respectively, as shown in Figure 8. The critical deformation stress at 220 ${ }^{\circ} \mathrm{C}$ first increases, then decreases, and finally smoothly changes with a decrease in the distance to the edge. The critical stress in R3 is the smallest. According to the statistics of the original grain size in Figures 6 and 7, the original average grain size before deformation in R3 is the smallest. Tan et al. [31] have proposed that a smaller

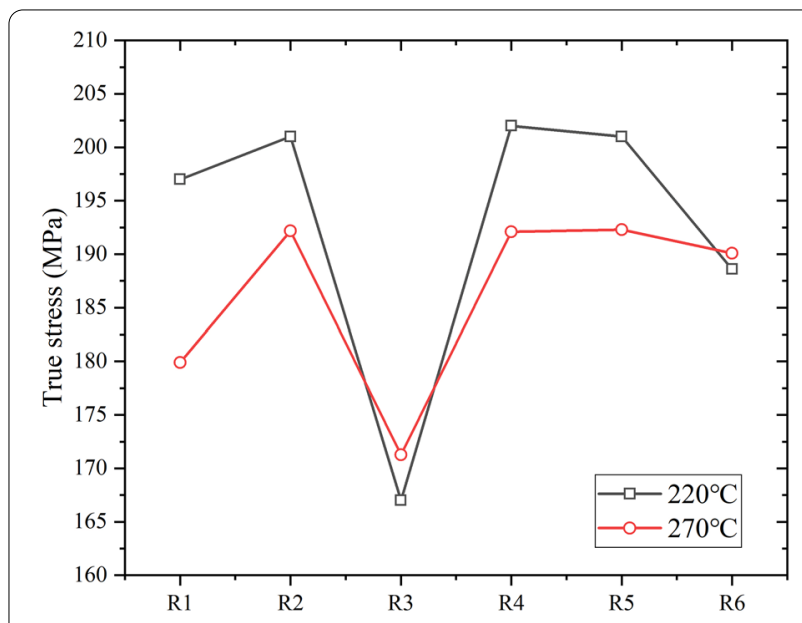

Figure 8 Critical stress values of different regions along the transverse direction
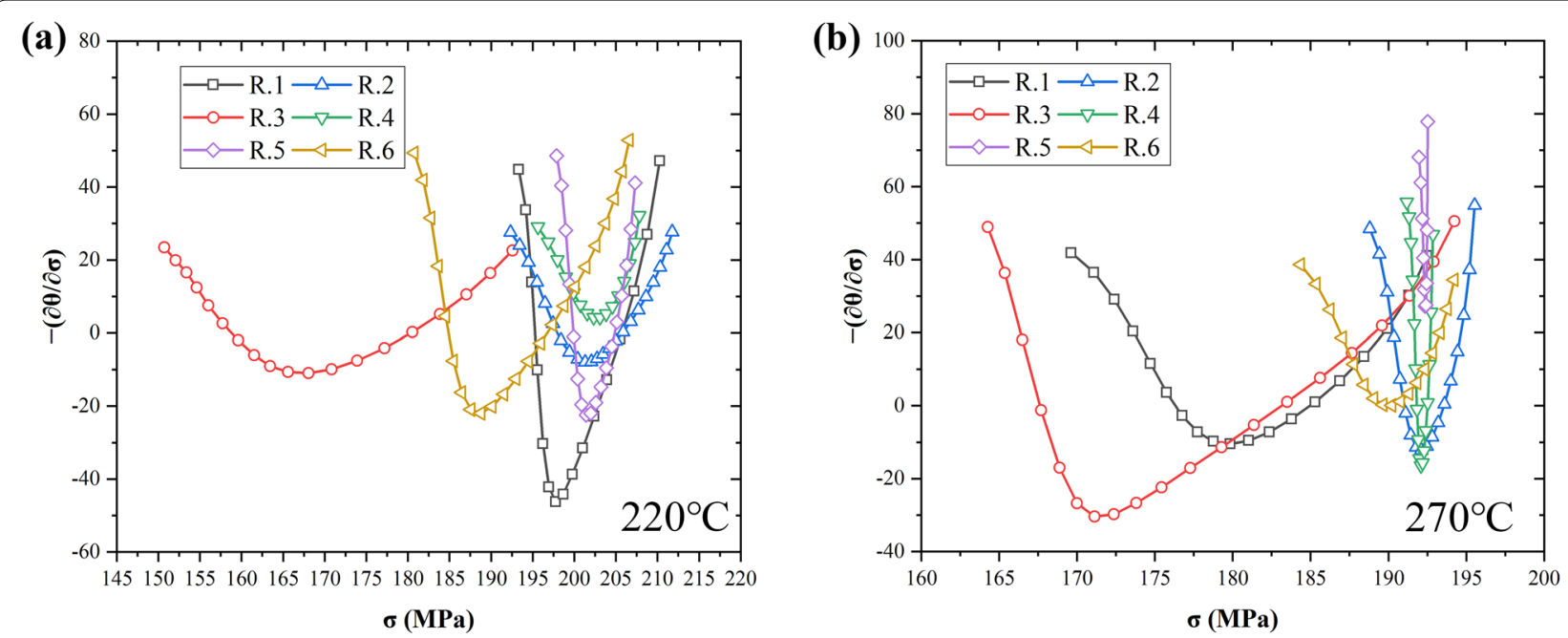

Figure $7-(\partial \theta / \partial \sigma)-\sigma$ curves of different regions at the strain rate of $15 \mathrm{~s}^{-1}$ and various temperatures 
grain size was more suitable for grain boundary sliding (GBS), and the grain size was more prone to DRX. In $\mathrm{R} 2$, R4, and R5, the critical stress values are almost equal and decrease to $188.6 \mathrm{MPa}$ at the most marginal region R6; however, the critical stress value is still much higher than that of R2. It can be inferred that the original average grain size of the edge is large, and the large grain does not easily coordinate during the deformation, which is required for a greater accumulated strain (i.e., higher critical stress value) for the DRX of the edge structure. The results show that, DRX of R3 preferentially occurred at $220{ }^{\circ} \mathrm{C}$. When the heat deformation temperature was $270{ }^{\circ} \mathrm{C}$, the flow stress from R1 to R6 was $179.9,192.1$, $171.27,192.1,192.3$, and 190.1 MPa. From the symmetry center to the edge area, the critical stress values at $270{ }^{\circ} \mathrm{C}$ exhibited similar variation to those at $220^{\circ} \mathrm{C}$. However, in comparison with $220{ }^{\circ} \mathrm{C}$, at the same area, recrystallization critical stress values at $270{ }^{\circ} \mathrm{C}$ were lower, which was mainly due to the higher-temperature atomic oscillation, and faster rate of diffusion. Thus, the driving force of the dislocation migration was stronger and the critical shear stress was lower, which led to the easier occurrence of DRX.

\subsection{Microstructure Observation}

Figure 9 shows that different microstructure morphologies result from different recrystallization states. Figure 9 indicates that the proportion of coarse and fine grains in R6 (the edge of the rolled plate) is relatively high, and the grain exhibits a clear bimodal state. In the entire field of view, the boundary of the original grain becomes jagged. Recrystallized grains with smaller sizes appear at the

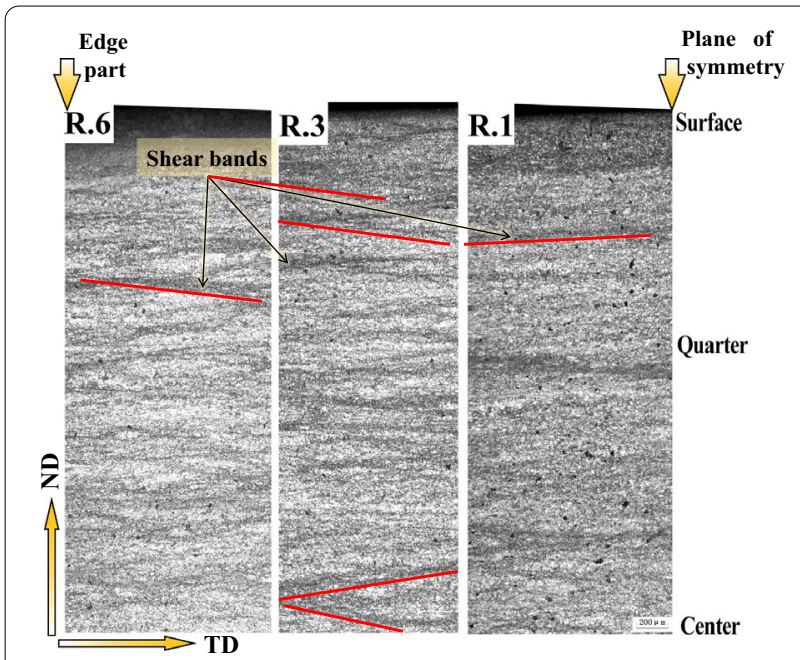

Figure 9 Microstructures in the thickness direction of the samples along the transverse direction of the as-rolled AZ31 plate with a thickness of $5.6 \mathrm{~mm}$ grain boundaries and trifurcation nodes of some coarse grains and surround the original coarse grain boundary. This is the typical initial state of DRX. This phenomenon occurs because the temperature in R6 is lower owing to the presence of a higher number of thermal convection surfaces. The driving stress required for DRX is larger (Figure 7), which results in recrystallization. Alternatively, the dislocation developed at the grain boundary caused by deformation exceeds its absorption capacity or the combination of lattice dislocation is in the incubation period; thus, the residual dislocation will accumulate at the grain boundary and generate local stress, which leads to the formation of a jagged grain boundary.

\subsection{Texture Evolution}

The microstructures, texture, and misorientation angle distribution were observed in the center place of the TD-ND plane, as shown in Figure 10. It can be seen from Figure 10 that the percentage of Low-angle-grainboundaries (LAGBs) in R6 is highest, followed by R1, and the minimum percentage is in R3. There are more Highangle-grain-boundaries (HAGBs) in the R3 region, which means that more recrystallization has taken place in this region and more LAGBs were converted into HAGBs. R1 region has a relatively low degree of dynamic recrystallization, due to the weak impact of shear. On the contrary, the region of R6 has a greater number of LAGBs and a lower recrystallization processing level. This phenomenon is related to the fact that R6 is on the edge of the plate, the region that is greatly affected by factors such as low temperature associated with more heat dissipation and unique stress states. In addition, there are a certain number of tensile twins at an angle of $86^{\circ}$ from the $C$ axis in the edge region. According to the IPF map shown in Figure10b, the number of grains in the random texture distribution in R3 increases to a certain extent, especially in the grains that had completed recrystallization.

The average grain size in R3 is $5.24 \mu \mathrm{m}$, the smallest in the transition zone of the rolled plate, which is consistent with the results of minimum critical stress required for R3 to initiate DRX, as shown in Figure 10e. An important reason for this result is that the original grain size in the intermediate transition region is small. Thus, GBS becomes the main deformation mechanism when the fineness rate is high [32,33]. Under the conditions of low driving stress and temperature, DRX can occur quickly to achieve steady-state flow characteristics. More importantly, more shear bands existed in R3 than in other regions, which means that a greater proportion of dynamically recrystallized grains will be induced to occur, which considerably contributes to grain refinement $[33,34]$. The average grain sizes in $\mathrm{R} 1$ is $5.67 \mu \mathrm{m}$, smaller than R6 at the edge. Although the temperature of 

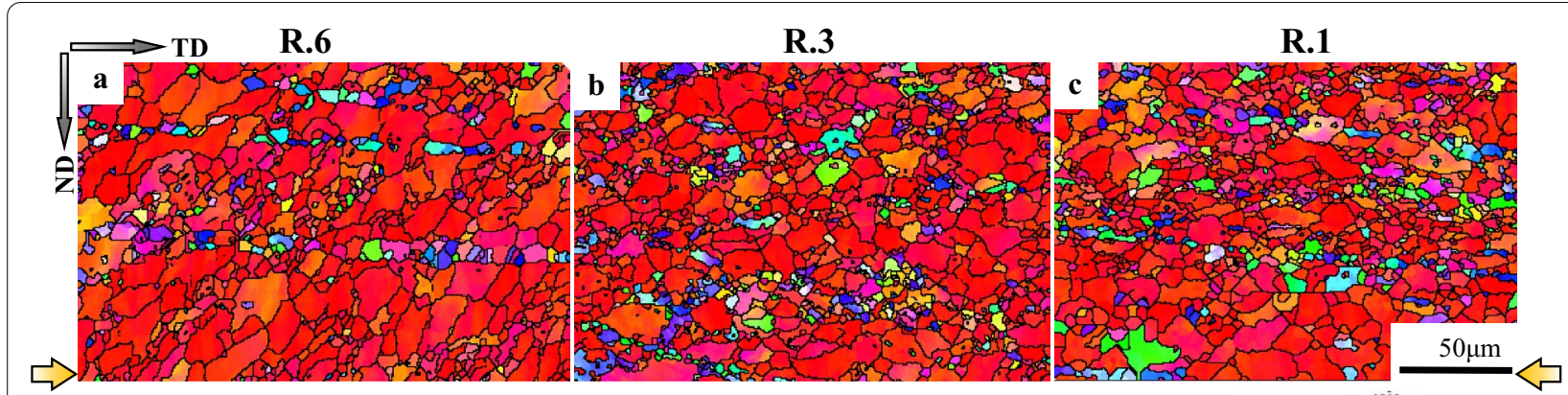

Edge part

Plane of
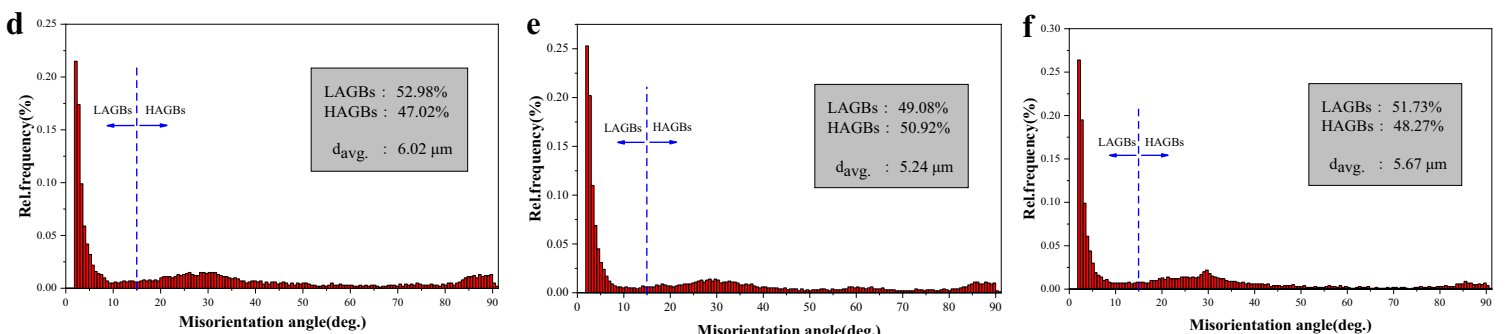

Figure 10 IPF maps and misorientation angle distribution near the center along the transverse direction of the as-rolled AZ31 plate with a thickness of $5.6 \mathrm{~mm}$ : (a, d) R6, (b, e) R3, (c, f) R1

the central part is higher than that of the edge owing to slow heat dissipation, the central part is also in the initial stage of DRX owing to the large original grain size and large critical stress required for DRX.

\section{Conclusions}

The hot deformation behavior of magnesium alloy plate in different width directions under the conditions of isothermal compression at $220{ }^{\circ} \mathrm{C}$ and $270{ }^{\circ} \mathrm{C}$ was analyzed. The structure evolution of different parts was observed and compared with the actual rolling test. The main results of this study are summarized as follows.

(1) When the magnesium alloy plate is subjected to a certain degree of cumulative reduction, the grain will no longer have a clear deflection, and grain orientation has little effect on the DRX of the material.

(2) Most of the AZ31 rolled plate areas showed the characteristics of typical DRX softening. When the deformation temperature increased from $220{ }^{\circ} \mathrm{C}$ to $270{ }^{\circ} \mathrm{C}$, strains corresponding to the highest peak stress decreased from 0.28 to 0.2 , which indicated that DRX occurred earlier at a higher temperature. For the temperature along the width direction from center to edge, the critical stress value performance first increases and then decreases after a smooth change trend. When the thermal deformation tem- perature is $220{ }^{\circ} \mathrm{C}$ and $270{ }^{\circ} \mathrm{C}$, the critical stress value in $\mathrm{R} 3$ is $167.3 \mathrm{MPa}$ and $171.27 \mathrm{MPa}$, respectively.

(3) The grains at the edge of the rolled plate (R6) were clearly bimodally distributed, which meant that DRX occurred late in this region. The average grain size in R3 is $5.24 \mu \mathrm{m}$, the smallest in the transition zone of the rolled plate. There are more High-anglegrain-boundaries (HAGBs) in the R3 region, which means that more recrystallization has taken place in this region and manifested a randomization distribution.

\section{Acknowledgements}

Not applicable.

\section{Authors' Information}

Chenchen Zhi, born in 1989, is currently a lecturer at School of Mechanical Engineering, Taiyuan University of Science and Technology, China. Her research interests include magnesium and forming.

Lifeng Ma, born in 1977, is currently the Dean of School of Mechanical Engineering, Taiyuan University of Science and Technology, China.

\section{Authors' Contributions}

$\mathrm{CZ}$ carried out the thermal compression test and the microstructure treatment, and the relevant data was also interpreted by CZ. She was a major contributor in writing the manuscript. LM provided guidance for the analysis and writing of the article. WJ collected literature in the Introduction part of this paper. PL analyzed the experimental data of the thermal compression test. QL provided the original cast material for this study. ZH guided the analysis of 
dynamic recrystallization behavior in the manuscript. TH guided the analysis of dynamic recrystallization behavior in the manuscript. All authors read and approved the final manuscript.

\section{Funding}

Supported by National Natural Science Foundation of China (Grant Nos. U1910213, U1610253, 51604181), and Shanxi Provincial Key Research and Development Program of China (Grant Nos. 201603D111004, 201803D121026).

\section{Competing Interests}

The authors declare no competing financial interests.

\section{Author Details}

${ }^{1}$ School of Mechanical Engineering, Taiyuan University of Science and Technology, Taiyuan 030024, China. ${ }^{2}$ Heavy Machinery Engineering Research Center of the Ministry of Education, Taiyuan University of Science and Technology, Taiyuan 030024, China. ${ }^{3}$ Key Lab of Electromagnetic Processing of Materials, Ministry of Education, Northeastern University, Shenyang 110819, China.

Received: 13 March 2020 Revised: 16 February 2021 Accepted: 25 August 2021

\section{Published online: 11 October 2021}

\section{References}

[1] M M Avedesian, H Baker. ASM speciality handbook: magnesium and magnesium alloys. ASM International, 1999: 274.

[2] D.Wu, R S Chen, E H Han. Excellent room-temperature ductility and formability of rolled Mg-Gd-Zn alloy sheets. Journal of Alloys \& Compounds, 2011, 509(6): 2856-2863.

[3] GW Groves, A Kelly. Independent slip systems in crystals. Philosophical Magazine, 1963, 8(89): 877-887.

[4] Y Cheng, Y Fu, Y Xin, et al. \{1012\} twinning behavior under biaxial tension of Mg-3Al-1Zn plate. International Journal of Plasticity, 2020, 132: 102754.

[5] HT Zhou, Q B Li, Z K Zhao, et al. Hot workability characteristics of magnesium alloy AZ80-A study using processing map. Materials Science and Engineering: A, 2010, 527(7-8): 2022-2026.

[6] SE Ion, F J Humphreys, S H White. Dynamic recrystallisation and the development of microstructure during the high temperature deformation of magnesium. Acta Metallurgica, 1982, 30(10): 1909-1919.

[7] C C Zhi, LF Ma, W T Jia, et al. Dependence of deformation behaviors on temperature for twin-roll casted AZ31 alloy by processing maps. Journal of Materials Research and Technology, 2019, 8(6): 5217-5232.

[8] G Garcés, E Oñorbe, W Gan, et al. Evolution of twinning in extruded AZ31 alloy with bimodal grain structure. Materials Characterization, 2017, 126: 116-124.

[9] H J Zhang, Antoine Jérusalem, Enrico Salvati, et al. Multi-scale mechanisms of twinning-detwinning in magnesium alloy AZ31B simulated by crystal plasticity modeling and validated via in situ synchrotron XRD and in situ SEM-EBSD. International Journal of Plasticity, 2019, 119: 43-56.

[10] T Al-Samman, K D Molodov, D A Molodov, et al. Softening and dynamic recrystallization in magnesium single crystals during c-axis compression. Acta Materialia, 2012,60(2): 537-545.

[11] S Anbuselvan, S Ramanathan. Hot deformation and processing maps of extruded ZE41A magnesium alloy. Materials \& Design, 2010 31(5): 2319-2323.

[12] M Pekguleryuz, M Celikin, M Hoseini, et al. Study on edge cracking and texture evolution during $150 \mathrm{C}$ rolling of magnesium alloys: the effects of axial ratio and grain size. Journal of Alloys and Compounds, 2012, 510(1): $15-25$.

[13] J Peng, B J Lü, Y B Hu, et al. Effect of rare-earth Y on microstructure and mechanical properties of as-cast Mg-2.0 Zn-0.3 Zr alloy. Rare Metal Materials and Engineering, 2010, 39(4): 672-677.

[14] G Bajargan, G Singh, D Sivakumar, et al. Effect of temperature and strain rate on the deformation behavior and microstructure of a homogenized
AZ31 magnesium alloy. Materials Science and Engineering: A, 2013, 579: 26-34.

[15] TW Wong, A Hadadzadeh, Wells Mary A. High temperature deformation behavior of extruded AZ31B magnesium alloy. Journal of Materials Processing Technology, 2017, 251: 360-368.

[16] WT Jia, L F Ma, Q C Le, et al. Deformation and fracture behaviors of AZ31B $\mathrm{Mg}$ alloy at elevated temperature under uniaxial compression. Journal of Alloys and Compounds, 2019, 783: 863-876.

[17] WY Hu, Q C Le, Z Q Zhang, et al. Numerical simulation of DC casting of AZ31 magnesium slab at different casting speeds. Journal of Magnesium and Alloys, 2013, 1(1): 88-93.

[18] Q Y Liao, Q Lan, WT Jia, et al. Microstructure and mechanical property inhomogeneities of a modified AZ80 magnesium alloy wide plate under horizontal flat die extrusion. Journal of Materials Engineering and Performance, 2019, 28(4): 1977-1985.

[19] C C Zhi, L F Ma, Q X Huang, et al. Improvement of magnesium alloy edge cracks by multi-cross rolling. Journal of Materials Processing Technology, 2018, 255: 333-339.

[20] O Sabokpa, A Zarei-Hanzaki, H R Abedi. An investigation into the hot ductility behavior of AZ81 magnesium alloy. Materials Science and Engineering: $A, 2012,550: 31-38$.

[21] J A D Valle, M T Pérez-Prado, O A Ruano. Texture evolution during largestrain hot rolling of the Mg AZ61 alloy. Materials Science and Engineering: A, 2003, 355(1-2): 68-78.

[22] R Ma, Y Q Zhao, Y N Wang. Grain refinement and mechanical properties improvement of AZ31 Mg alloy sheet obtained by two-stage rolling. Materials Science and Engineering: A, 2017, 691: 81-87.

[23] R B Sims. The calculation of roll force and torque in hot rolling mills. Proceedings of the Institution of Mechanical Engineers, 1954, 168(1): 191-200.

[24] A Fatemi, L Yang. Cumulative fatigue damage and life prediction theories: a survey of the state of the art for homogeneous materials. International Journal of Fatigue, 1998, 20(1): 9-34.

[25] T Murai, S I Matsuoka, S Miyamoto, et al. Effects of extrusion conditions on microstructure and mechanical properties of AZ31B magnesium alloy extrusions. Journal of Materials Processing Technology, 2003, 141(2): 207-212.

[26] T Sakai, J J Jonas. Overview no.35 dynamic recrystallization: mechanical and microstructural considerations. Acta Metallurgica, 1984, 32(2): 189-209.

[27] D L Yin, K F Zhang, G F Wang. Warm deformation behavior of hot-rolled AZ31 Mg alloy. Materials Science and Engineering: A, 2005, 392(1-2): 320-325.

[28] Y C Lin, M S Chen, J Zhong. Microstructural evolution in 42CrMo steel during compression at elevated temperatures. Materials Letters, 2008, 62(14): 2132-2135.

[29] A Galiye, R Kaibyshev, G Gottstein. Correlation of plastic deformation and dynamic recrystallization in magnesium alloy ZK60. Acta Materialia, 2001, 49(7): 1199-1207.

[30] S Kumar, D Samantaray, B Aashranth, et al. Dependency of rate sensitive DRX behaviour on interstitial content of a Fe-Cr-Ni-Mo alloy. Materials Science and Engineering: A, 2019, 743: 148-158.

[31] J C Tan, M J Tan. Dynamic continuous recrystallization characteristics in two stage deformation of Mg-3Al-1Zn alloy sheet. Materials Science and Engineering: A, 2003, 339(1-2): 124-132.

[32] X Y Yang, M Sanada, H Miura, et al. Effect of initial grain size on deformation behavior and dynamic recrystallization of magnesium alloy AZ31. Materials Science Forum, 2005, 488-489: 223-226.

[33] CYXu, FX Chu, X L Xu, et al. Influence of grain size on dynamic recrystallization of AZ31 magnesium alloy rolling sheet. Applied Mechanics and Materials, 2013, 395-396: 218-222.

[34] Z Zhang, M P Wang, N Jiang, et al. Formation of shearing bands in the hot-rolling process of AZ31 alloy. Journal of Alloys and Compounds, 2012, 512(1): 73-78 